\title{
Relative loudness judgments of material presented
}

dichotically

D. R. DAVIES and A. J. CHAPMAN, University of Leicester, Leicester, England

Three groups of 12 Ss listened to white noise of 80,90 , or $115 \mathrm{~dB}$ presented to one ear, while they shadowed words presented at an intensity of $90 \mathrm{~dB}$ to the other ear. Subsequently, they were asked to judge whether the noise or the speech was louder or if they were of the same intensity. All 12 Ss judged 90-dB shadowed speech to be louder than 80-dB noise, 11 out of 12 Ss judged 90-dB shadowed speech to be louder than 90-dB noise, and 8 out of 12 Ss judged 90-dB shadowed speech to be louder than 115-dB noise. The results are interpreted as providing some support for Treisman's filter-amplitude theory of attentional selection.

Treisman (1960) has put forward a filter amplitude model of attentional selection that, inter alia, suggests that the process of selection between two sensory channels results in an attenuation of messages on the channel away from which attention has been directed. Thus if, in a dichotic listening situation, $S$ is required to "shadow" (that is, to repeat items as soon as they are presented) material presented to one ear and if different material of the same intensity is presented to the other ear then it should be judged as being of lower intensity. However, Neisser (1967) has argued (1) that such judgments would be very difficult to make and (2) that only small differences between the judgments of relative intensity would appear. The present study seeks to examine these possibilities by requiring $S s$ to make relative loudness judgments of shadowed speech presented to one ear and of white noise presented to the other.

$$
\text { METHOD }
$$

The Ss were 36 university students, 18 men and 18 women, between 18 and 24 years of age, who volunteered to take part in the experiment. When they were being recruited, they were informed that the experiment was concerned with the effects of noise on the learning of verbal material, but once the experiment was completed they were told the real nature and purpose of the study. Ss were tested individually.

In order to see if loudness judgments differed between ears, $S s$ were first asked to make relative loudness judgments with reference to a standard noise burst following the sequential presentation via headphones of 5 -sec bursts of white noise of different intensities to one ear only. This procedure was then repeated for the other ear. Subsequently, Ss were asked to make relative loudness judgments following the simultaneous presentation of a 1-min burst of white noise to both ears. In this case, the intensity of the white noise presented to one ear was different from that presented to the other ear, and Ss were asked to judge whether the two intensities were the same or different; if they judged them to be different, they were asked to say which was the louder. These two procedures were used to select Ss whose judgments of relative intensity showed no systematic difference between ears. Five Ss who showed such a difference were dropped from the main experiment and replaced by new Ss.

For the main experiment, Ss were divided into three groups of 12, each group containing six men and six women. A tape-recorded test list of 10 words, each word being repeated 10 times in random order, was presented at an intensity of $90 \mathrm{~dB}$ (re .0002 dynes $/ \mathrm{cm}^{2}$ ) to one ear, and 80-dB white noise (for Group 1), 90-dB white noise (for Group 2), or 115-dB white noise (for Group 3) was presented to the other. Ss were required to "shadow" the word list, and in each group three men and three women were required to shadow material presented to the right ear and three men and three women to shadow material presented to the left.

Before the test list was given, a tape-recorded practice list was presented to the same ear in which Ss would hear the test list. The practice list, which Ss were required to shadow, also consisted of 10 words repeated 10 times in random order, and during the practice nothing was presented to the other ear. The words constituting the practice and test lists are shown in Table 1. The words were all disyllabic and were all taken from the AA word frequency count in the

Table 1

Words Used in the Practice and Test Lists

\begin{tabular}{ll}
\hline Practice Iist & Test List \\
\hline Employ & Science \\
Distant & Hero \\
Model & Flashing \\
Herald & Metal \\
Perfect & Bitter \\
Tremble & Cabin \\
Quarrel & Obey \\
Lion & Witness \\
Invite & Tower \\
Active & Vessel \\
\hline
\end{tabular}

Thorndike-Lorge word frequency list (Thorndike \& Lorge, 1944). The duration of each word list, 100 words in all, was approximately $3 \mathrm{~min} 20 \mathrm{sec}$. After the practice period, Ss were informed that another list of words would now be presented to the same ear and that masking noise would be fed to the other ear. They were again asked to shadow the words. Before the practice and test lists were presented, $E$ read out each of the 10 words from the appropriate list and ensured that Ss understood them. In spite of this, articulation errors occurred during the shadowing of both practice and test lists.

Following the presentation of the test list, Ss were asked to judge which of the two sources was the louder, the noise or the speech. They were then given a recognition test consisting of the 10 test words and 30 new words, all disyllabic and all taken from the AA frequency count in the Thorndike-Lorge word frequency list. Ss were required to find as many of the words in the test list as they could.

\section{RESULTS AND DISCUSSION}

Omission and intrusion errors on the recognition test were compared for Groups 1,2 , and 3. These are shown in Table 2. As might be expected, Group 3 made more errors of both kinds than Group 2 and Group 2 make more than Group 1. Men made slightly more omission errors and about the same number of intrusion errors as women, and slightly more omission and intrusion errors were made by Ss shadowing material presented to their left ears than by those shadowing material presented to their right. Since these differences are only of peripheral interest, they will not be discussed further.

The numbers of Ss in each of the three conditions judging either noise or speech to be louder, or judging that the two intensities were the same, are shown in Table 3. These data were analyzed by means of the binomial test (Siegel, 1956), which requires the data to be classified into two categories rather than three. This presents no problems for the analysis of the data of Groups 1 and 2 since a maximum of two categories were used. No calculation was performed on the results for Group 1 since all results were in the expected direction, and for Group 2 the probability of one nonspeech response being given on a chance basis was 0.0003 .

Table 2

Number of Omission and Intrusion Errors Made

\begin{tabular}{ccc}
$\begin{array}{c}\text { Number of } \\
\text { by }\end{array}$ & $\begin{array}{c}\text { Number of } \\
\text { Omission } \\
\text { Errors }\end{array}$ & $\begin{array}{c}\text { Intrusion } \\
\text { Errors }\end{array}$ \\
Group & 3 & 2 \\
1 & 13 & 12 \\
2 & 22 & 33 \\
\hline
\end{tabular}


Table 3

Number of Ss Making the Three Possible Loudness Judgments in Each of the Three Experimental Conditions

\begin{tabular}{|c|c|c|c|c|c|}
\hline Group & $\begin{array}{l}\text { Noise } \\
\text { Level }\end{array}$ & $\begin{array}{c}\text { Speech } \\
\text { Level }\end{array}$ & $\begin{array}{c}\text { Number of } \\
\text { Ss Saying } \\
\text { Noise } \\
\text { Louder }\end{array}$ & $\begin{array}{l}\text { Number of } \\
\text { Ss Saying } \\
\text { Speech } \\
\text { Louder }\end{array}$ & $\begin{array}{l}\text { Number of } \\
\text { Ss Saying } \\
\text { the Same } \\
\text { Intensity }\end{array}$ \\
\hline 1 & $80 \mathrm{~dB}$ & $90 \mathrm{~dB}$ & 0 & 12 & 0 \\
\hline 2 & $90 \mathrm{~dB}$ & $90 \mathrm{~dB}$ & 0 & 11 & 1 \\
\hline 3 & $115 \mathrm{~dB}$ & $90 \mathrm{~dB}$ & 2 & 8 & 2 \\
\hline
\end{tabular}

However, all three categories occur in Group 3. If a two-way classification is made in terms of speech and nonspeech responses, then eight speech responses must be compared with four nonspeech responses. The probability of four nonspeech responses being given on a chance basis is 0.194 . If, on the other hand, a two-way classification is made in terms of white noise and nonwhite noise responses, which seems reasonable since it would be surprising if only two Ss had judged 115-dB white noise to be louder than $90-\mathrm{dB}$ speech, the probability of obtaining $2 / 12$ white noise responses is 0.019 . It is worth adding that, while shadowing, all Ss in Group 3 were shouting the words as they heard them.

Thus, a significant proportion of Ss judged 90-dB shadowed speech as louder than $90-\mathrm{dB}$ white noise and a surprisingly high proportion, significantly so if the above argument is accepted, judged $90-\mathrm{dB}$ shadowed speech to be louder than 115-dB white noise. It should be noted, however, that while the judgments of relative loudness appeared easy to make for Ss in Groups 1 and 2, they were much more difficult to make for Ss in Group 3. If we had taken confidence ratings, we would have more precise evidence to offer in this connection.

In conclusion, it seems that the findings of this study lend some support to Treisman's filter-amplitude theory and run counter to Neisser's suggestion referred to above. It appears likely that the act of switching attention to one ear does result in some attenuation of material presented to the other, even when this material is presented at a considerably higher intensity. It would be of interest to see if the same findings are obtained when speech of different intensities is presented to the two ears in a dichotic listening situation.

\section{REFERENCES}

NEISSER, U. Cognitive psychology. New York Appleton-Century-Crofts, 1967.

SIEGEL, S. Non-parametric statistics. New York: McGraw-Hill, 1956.

THORNDIKE, E. L., \& LORGE, I. The teacher's word book of 30,000 words. New York: Bureau of Publications, Teachers College, Columbia University, 1944.

TREISMAN, A. M. Contextual cues in selective listening. Quarterly Journal of Experimental Psychology, 1960, 12, 242-248. NOTE

1. We should like to thank Dr. J. T. Reason for his helpful comments on an earlier draft of this paper. involved in the retention of verbal information. Waugh \& Norman (1965) have used the terms primary memory (PM) and secondary memory (SM) in referring to these mnemonic processes. PM is viewed as a system of very limited capacity that receives and maintains information by rehearsal for several seconds until it can be transferred to SM, a system of much larger capacity where the information can be maintained indefinitely.

Support for such a distinction has come from studies that have shown different stimulus properties to be important in short-term and long-term retention, suggesting that $\mathrm{PM}$ and $\mathrm{SM}$ involve different modes of storage. There is a good deal of evidence that indicates that short-term retention is significantly influenced by the acoustic and/or articulatory (A) ${ }^{1}$ similarity between the items to be recalled (Conrad, 1964; Wickelgren, 1965; Baddeley, 1966), but that long-term retention is influenced by the semantic (S) similarity between the items (Underwood \& Goad, 1951; Baddeley \& Dale, 1966).

Recently, several studies have shown short-term retention to be influenced by semantic factors as well (Wickens \& Eckler, 1968; Wickens \& Simpson, 1968; Conrad, Freeman, \& Hull, 1965). These findings would seem to question the use of $A$ and $S$ effects as a basis for distinguishing between PM and SM. However, Waugh and Norman's model would seem to be able to account for these seemingly discrepant findings. Their model assumes that PM and SM are not mutually exclusive systems, but, rather, that they overlap in time. Therefore, the probability that an item is in PM is highest immediately after presentation and declines over the retention interval, while the probability that the item is in SM is lowest immediately after presentation and increases over the same interval. Both PM and SM would therefore be expected to affect retention, even over short intervals. Those studies showing S effects in a STM task have used relatively long retention intervals $(25 \mathrm{sec})$, while those showing an A effect have used short intervals $(6 \mathrm{sec})$. Waugh and Norman have argued that most of the data from STM studies actually reflect the properties of both systems.

The purpose of the present experiment is to test for an interaction between type of similarity and the length of the retention interval. If the storage mode is $A$ in $P M$ and $S$ in SM and if the assumptions of Waugh and Norman are correct, A similarity should have its greatest effect after a short retention interval, while $S$ similarity should have its greatest effect after a long interval. 